\title{
Letak Conus Medularis terhadap Vertebra Menggunakan Hasil Pencitraan Magnetic Resonance Imaging di Rumah Sakit Dr. Hasan Sadikin Bandung untuk Anestesi Spinal
}

\author{
Nurfitriani, ${ }^{1}$ Abdul Muthalib Nawawi, ${ }^{2}$ Dedi Fitri Yadi, ${ }^{2}$ Farhan Anwary ${ }^{2}$ \\ ${ }^{1}$ Bagian Anestesi Rumah Sakit Sayang Ibu Balikpapan, \\ ${ }^{2}$ Departemen Anestesiologi dan Terapi Intensif \\ Fakultas Kedokteran Universitas Padjadjaran/Rumah Sakit Dr. Hasan Sadikin Bandung
}

\begin{abstract}
Abstrak
Kepentingan dari conus medularis bagi dokter spesialis anestesi adalah saat dilakukan tindakan anestesi spinal yang memiliki risiko terjadi trauma medula spinalis yang serius. Conus medularis dapat diidentifikasi melalui hasil pencitraan magnetic resonance imaging (MRI). Penelitian yang dilakukan sekarang bertujuan untuk mengetahui distribusi letak ujung conus medularis pada orang Indonesia secara observasional deskriptif dengan menggunakan hasil pencitraan magnetic resonance imaging (MRI) lumbosakral. Penelitian dilakukan melalui pemeriksaan terhadap letak ujung conus medularis secara retrospektif pada 135 hasil pencitraan MRI pasien usia 18-65 tahun dari bulan Januari 2013 hingga Maret 2014 di Departemen Radiologi Rumah Sakit Dr. Hasan Sadikin Bandung. Dari penelitian ini didapatkan letak ujung conus medularis paling banyak berada setinggi sepertiga tengah L1, dengan rentang mulai dari setinggi sepertiga tengah T12 hingga sepertiga bawah L2. Berdasarkan parameter jenis kelamin didapatkan distribusi letak conus medularis pada perempuan cenderung lebih kaudal dibandingkan dengan laki-laki.
\end{abstract}

Kata kunci: Conus medularis, magnetic resonance imaging, orang Indonesia

\section{Determination of Conus Medullaris Position within the Vertebra using Magnetic Resonance Imaging in Dr. Hasan Sadikin General Hospital Bandung for Spinal Anesthesia Purpose}

\begin{abstract}
The position of conus medullaris is important to be identified by anesthesiologists during spinal anesthesia to avoid serious spinal cord trauma risk. Conus medullaris can be accurately identified through magnetic resonance imaging (MRI) images. The aim of this study was to determine the distribution of conus medullaris in Indonesians through a descriptive observation using magnetic resonance imaging (MRI) images of lumbosacral. The locations of conus medullaris were observed retrospectively on 135 MRI images scanned, aged 18-65 years, during the period of January 2013 to March 2014 at the Departement of Radiology, Dr. Hasan Sadikin General Hospital Bandung. From this study, it was revealed that the conus medullaris are mostly located at the middle third of L1, ranging from the middle third of T12 to the lower third of L2. With gender as a parameter, it was shown that the distribution of conus medullaris in women tends to be more caudal than in men.
\end{abstract}

Key words: Conus medullaris, Indonesian, magnetic resonance imaging

Korespondensi: Nurfitriani, dr., SpAn, Bagian Anestesi Rumah Sakit Sayang Ibu, Jl. Asoka 33 RT. 37 GSI Balikpapan, Telp. 0542-422088, Mobile 0812-53263084,Email nurfitriani84@gmail.com 


\section{Pendahuluan}

Prosedur anestesia neuraksial spinal yang telah dilakukan di Rumah Sakit Dr. Hasan Sadikin (RSHS) Bandung pada periode MeiAgustus 2013 adalah sejumlah 791 dari 5.727 kasus operasi $(13,81 \%)$. Teknik anestesia spinal dilakukan dengan menyuntikkan obat anestesia lokal ke dalam rongga subaraknoid setinggi vertebra antara lumbal 2 dan lumbal $3\left(\mathrm{~L}_{2-3}\right)$ hingga $\mathrm{L}_{4-5}{ }^{1-3}$

Salah satu komplikasi yang dapat terjadi akibat prosedur anestesia neuraksial adalah kerusakan saraf permanen. Defisitneurologis yang dapat terjadi adalah disestesia, nyeri, hingga kelemahan ekstremitas bawah. Salah satu penyebab kerusakan saraf tersebut ialah trauma langsung pada medula spinalis yang diakibatkan tusukan jarum spinal. Beberapa faktor yang dapat berpotensi mengakibatkan trauma medula spinalis antara lain adalah kesalahan pada saat mengidentifikasi celah intervertebralis dan juga letak ujung conus medularis yang lebih rendah daripada yang diperkirakan. ${ }^{4}$

Diameter ujung medula spinalis berangsur menjadi kecil sepanjang $<5 \mathrm{~cm}$. Medula spinalis yang rata-rata berdiameter $1,5 \mathrm{~cm}$ berangsur menjadi $\pm 2,0 \mathrm{~mm}$. Titik medula spinalis yang tidak mengecil tersebut dikenal sebagai ujung conus medularis. Pada orang dewasa, ujung conus medularis paling banyak terletak pada $\mathrm{L}_{1}$ atau $\mathrm{L}_{2}$, terkadang di torakal $12\left(\mathrm{~T}_{12}\right)$ atau bahkan di $\mathrm{L}_{3^{1,3,5-7}}$ Ujung conus medularis tersebut dapat diidentifikasi dengan akurasi tinggi melalui bantuan pencitraan magnetic resonance imaging (MRI). ${ }^{8}$

Beberapa penelitian tentang penentuan ujung conus medularis dengan pencitraan MRI telah dilakukan oleh berbagai negara, antara lain Turki, Iran, dan juga Korea. Hasil penelitian tersebut menyatakan letak conus medularis yang berbeda, ${ }^{9-12}$ sedangkan letak ujung conus medularis pada orang Indonesia sendiri belum ditemukan data resmi.

Penelitian ini bertujuan untuk mengetahui distribusi letak ujung conus medularis pada orang Indonesia dengan menggunakan hasil pencitraan MRI lumbosakral.

\section{Subjek dan Metode}

Penelitian ini adalah penelitian yang bersifat observasional deskriptif melalui pengambilan data dengan cara cross sectional retrospektif terhadap hasil pencitraan magnetic resonance imaging (MRI) daerah lumbal di Departemen Radiologi RSHS pada pasien dengan diagnosis radikulopati dari bulan Januari 2013-Maret 2014. Kriteria inklusi adalah foto MRI lumbal pasien yang berusia 18-65 tahun.

Kriteria eksklusi adalah foto MRI lumbal pasien dengan riwayat operasi pada vertebra, tumor vertebra, kelainan kongenital vertebra, serta fraktur pada vertebra. Pembacaan hasil pencitraan MRI untuk menentukan letak conus medularis dilakukan oleh dokter ahli radiologi Departemen Radiologi Rumah Sakit Dr. Hasan Sadikin Bandung. Pada vertebra yang setingkat dengan conus medularis akan dibagi menjadi 4 bagian, yaitu sepertiga atas, sepertiga tengah, sepertiga bawah, serta celah intervertebalis. Pembagian kelompok dilakukan berdasarkan jenis kelamin.

\section{Hasil}

Penelitian dilakukan terhadap 135 foto MRI, terdiri atas laki-laki sebanyak 56 foto (41\%) dan perempuan 79 foto (59\%). Usia terbanyak objek penelitian adalah 55 tahun sebanyak 9 foto (7\%), dengan rentang usia 18-65 tahun, usia rata-rata 48,7 tahun $(S D \pm 11,7)$. Pada hasil penelitian didapatkan bahwa conus medularis yang paling banyak berakhir setinggi sepertiga tengah $\mathrm{L}_{1}$ yaitu sebanyak 38 foto MRI (28\%). Lokasi paling tinggi pada sepertiga tengah $\mathrm{T}_{12}$ sebanyak 3 foto MRI (2,2\%), sedangkan paling rendah berada pada sepertiga bawah $\mathrm{L}_{2}$ sebanyak 4 foto MRI (3\%; Tabel).

Letak conus medularis pada foto MRI lakilaki yang paling banyak ialah sepertiga tengah $\mathrm{L}_{1}$ sebanyak 22 foto MRI (39\%). Letak conus medularis paling tinggi berada pada sepertiga tengah $\mathrm{T}_{12}$ sebanyak 3 foto MRI (5\%) serta paling rendah berada pada sepertiga tengah $\mathrm{L}_{2}$ sebanyak 3 foto MRI (5\%; Tabel). Pada foto MRI perempuan, letak conus medularis 
Tabel Letak Conus Medularis

\begin{tabular}{lcccccc}
\hline \multicolumn{1}{c}{$\begin{array}{c}\text { Letak Ujung Conus } \\
\text { Medularis }\end{array}$} & \multicolumn{3}{c}{ Jumlah Ujung Conus Medularis } & \multicolumn{3}{c}{ Total } \\
\cline { 2 - 7 } & Perempuan & $\mathbf{9}$ & Laki-laki & $\mathbf{\%}$ & Jumlah & $\%$ \\
\hline $1 / 3$ tengah $\mathrm{T}_{12}$ & 0 & 0 & 3 & 5 & 3 & 2 \\
$1 / 3$ bawah $\mathrm{T}_{12}$ & 2 & 3 & 0 & 0 & 2 & 2 \\
$\mathrm{~T}_{12}-\mathrm{L}_{1}$ & 1 & 1 & 0 & 0 & 1 & 1 \\
$1 / 3$ atas $\mathrm{L}_{1}$ & 11 & 14 & 7 & 13 & 18 & 13 \\
$1 / 3$ tengah $\mathrm{L}_{1}$ & 16 & 20 & 22 & 39 & 38 & 28 \\
$1 / 3$ bawah $\mathrm{L}_{1}$ & 17 & 22 & 7 & 13 & 24 & 18 \\
$\mathrm{~L}_{1}-\mathrm{L}_{2}$ & 7 & 9 & 3 & 5 & 10 & 7 \\
$1 / 3$ atas $\mathrm{L}_{2}$ & 9 & 11 & 11 & 20 & 20 & 15 \\
$1 / 3$ tengah $\mathrm{L}_{2}$ & 12 & 15 & 3 & 5 & 15 & 11 \\
$1 / 3$ bawah $\mathrm{L}_{2}$ & 4 & 5 & 0 & 0 & 4 & 3 \\
\hline
\end{tabular}

paling banyak berada pada sepertiga bawah $\mathrm{L}_{1}$ sebanyak 17 foto MRI (22\%), paling tinggi berada pada sepertiga bawah $\mathrm{T}_{12}$ sebanyak 2 foto MRI (3\%) dan paling rendah berada pada sepertiga bawah $L_{2}$ sebanyak 4 foto MRI (5\%; Tabel).

\section{Pembahasan}

Kepentingan mengetahuiletak conus medularis bagi dokter spesialis anestesia adalah pada saat melakukan anestesia spinal. Pada penelitian sebelumnya didapatkan hasil bahwa terdapat perbedaan pada lokasi conus medularis. Conus medularis yang pernah diteliti terletak mulai setinggi sepertiga tengah $\mathrm{T}_{11}$ hingga sepertiga bawah $\mathrm{L}_{3}$. Letak conus medularis dapat dinilai melalui pencitraan MRI. Magnetic resonance imaging diketahui mampu memberi gambaran anatomi lumbosakral dengan tingkat akurasi yang tinggi. ${ }^{8}$

Cukup sulit mendapatkan hasil pencitraan MRI pada manusia normal dalam jumlah yang banyak, maka objek pada penelitian-penelitian sebelumnya mempergunakan hasil pencitraan MRI dari pasien yang datang dengan keluhan nyeri punggung bagian bawah. ${ }^{9-12}$ Penelitian ini menggunakan hasil pencitraan MRI pasien yang didiagnosis radikulopati. Usia terbanyak dari 135 foto MRI yang diteliti adalah 55 tahun sebanyak 9 foto (7\%) dengan rentang usia 1865 tahun.

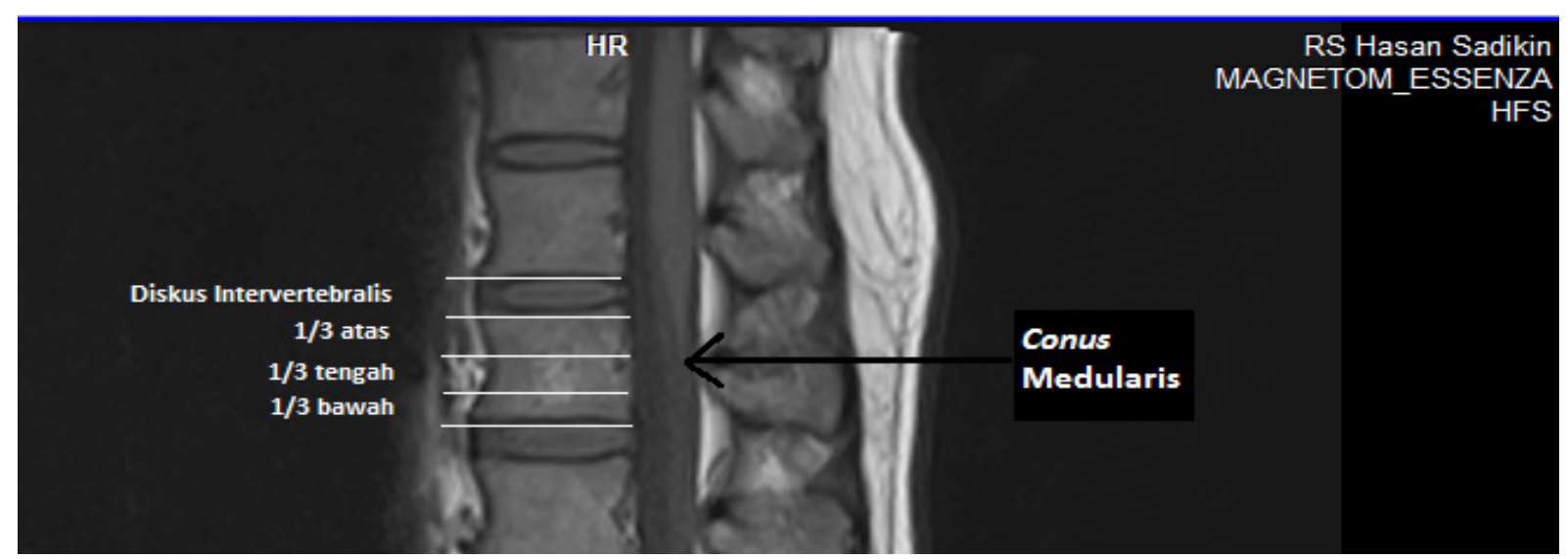

Gambar Letak Conus Medularis dan Pembagian Vertebra 
Pada penelitian ini didapatkan bahwa letak conus medularis berada dalam rentang mulai dari sepertiga tengah $\mathrm{T}_{12}$ hingga sepertiga bawah $\mathrm{L}_{2}$ yang masih berada dalam distribusi normal. Rentang ini lebih sempit dibandingkan dengan penelitian-penelitian yang dilakukan sebelumnya yang memberikan gambaran letak conus medularis dapat mencapai hingga $\mathrm{L}_{3}{ }^{9-12}$ Letak conus medularis penelitian ini paling banyak berada pada sepertiga tengah $\mathrm{L}_{1}$ Hasil penelitian ini lebih rendah jika dibandingkan dengan hasil penelitian di Turki, yaitu setinggi diskus intervertebralis $\mathrm{T}_{12}-\mathrm{L}_{1}$ serta Iran, yaitu pada sepertiga atas $\mathrm{L}_{1} \cdot{ }^{9-11}$ Hasil penelitian ini lebih tinggi bila dibandingkan dengan hasil penelitian di Korea, yaitu sepertiga bawah $\mathrm{L}_{1}{ }^{10}$

Pada penelitian ini didapatkan letak conus medularis pada foto MRI perempuan paling banyak berakhir setinggi sepertiga bawah $\mathrm{L}_{1}$ (22\%), satu segmen lebih rendah dari foto MRI laki-laki yang berada paling banyak pada sepertiga tengah $\mathrm{L}_{1}(39 \%)$. Letak tertinggi dari conus medularis pada foto MRI perempuan terletak pada daerah sepertiga bawah $\mathrm{T}_{12}$, satu segmen lebih rendah dari foto MRI laki-laki yang terletak mulai dari sepertiga tengah $\mathrm{T}_{12}$. Selain itu, letak conus medularis pada foto MRI perempuan yang berada di bawah sepertiga tengah $\mathrm{L}_{1}$ mencapai $62 \%$, lebih besar daripada foto MRI laki-laki yang hanya mencapai $43 \%$. Hal ini menunjukkan bahwa distribusi letak conus medularis pada foto MRI perempuan terletak lebih kaudal bila dibandingkan dengan foto MRI laki-laki. Hasil ini serupa dengan hasil yang diperoleh dari penelitian yang dilakukan di Turki serta Korea yang menyatakan bahwa conus pada wanita terletak lebih kaudal dari pria. ${ }^{9,10}$ Kondisi ini kemungkinan disebabkan panjang kolumna vertebralis pada perempuan yang lebih pendek dibandingkan dengan lakilaki. ${ }^{13}$

Pada penelitian ini diperoleh letak conus medularis berada di bawah sepertiga tengah $\mathrm{L}_{1}$ mencapai $54 \%$, lebih besar daripada hasil yang diperoleh dari penelitian yang dilakukan di Turki (43\%). Hal ini menunjukkan bahwa distribusi letak conus medularis pada orang Indonesia ternyata terletak lebih kaudal. Hal tersebut kemungkinan dipengaruhi oleh tinggi badan rata-rata orang Indonesia yang lebih rendah. Tinggi badan rata-rata perempuan di Turki adalah 158,9 cm dan laki-laki $174,1 \mathrm{~cm},{ }^{14}$ sedangkan di Indonesia, tinggi badan rata-rata untuk perempuan adalah $147 \mathrm{~cm}$ dan laki-laki $158 \mathrm{~cm}^{15}$

Rentang letak conus medularis pada hasil penelitian ini mencapai 10 segmen vertebra, yaitu sepertiga tengah $\mathrm{T}_{12}$ hingga sepertiga bawah $\mathrm{L}_{2}$. Persentase letak yang paling banyak dari conus medularis adalah $28 \%$ berada di sepertiga tengah $\mathrm{L}_{1}$, namun perlu diperhatikan bahwa persentase pada letak conus medularis yang tersebar pada sembilan segmen lainnya mencapai 72\%, dengan 54\% tersebar di bawah dari sepertiga tengah $\mathrm{L}_{1}$. Hal ini menunjukkan bahwa nilai rata-rata pada hasil penelitian ini kurang menggambarkan letak conus medularis rata-rata orang Indonesia, serta hal yang lebih penting untuk diketahui ialah distribusi letak conus medularis yang lebih besar berada di bawah sepertiga tengah $\mathrm{L}_{1}$.

\section{Simpulan}

Distribusi ujung conus medularis pada orang Indonesia paling banyak terletak pada setinggi sepertiga tengah $\mathrm{L}_{1}$, dengan kecenderungan letak conus medularis yang lebih kaudal pada perempuan.

\section{Daftar Pustaka}

1. Morgan GE, Mikhail MS, Murray MJ, penyunting. Clinical anesthesiology. Edisi ke-5. New York: McGraw-Hill Companies; 2013.

2. Aitkinhead AR, Smith G, Rowbotham DJ. Local anaesthetic techniques. Dalam: Aitkinhead AR, Smith G, Rowbotham DJ, penyunting. Textbook of anesthesia. Edisi ke-5. United Kingdom: Churchill Livingstone; 2007. hlm. 555-67.

3. Brown DL. Spinal, epidural, and caudal anesthesia. Dalam: Miller RD, penyunting. Miller's anesthesia. Edisi ke-7. United States of America: Churchill Livingstone; 2009. hlm. 1611-38.

4. Brown AR. Nerve damage following 
central neuraxial blockade. Revista Mexicana de Anestesiologia. 2008; 31(1):56-61.

5. Ellis H, Feldman S, Harrop-Griffiths W. Anatomy for anaesthetists. London: Blackwell Publishing; 2004.

6. Warren DT, Liu SS. Neuraxial anesthesia. Dalam: Longnecker DE, Brown DL, Newman MF, Zapol WM, penyunting. Anesthesiology. United states of America: McGraw Hill; 2008. hlm. 978-1008.

7. Moore Keith L, Dailey Arthur F, Agur Anne MR. Clinically oriented anatomy. Edisi ke-6. Philadelphia: Lippincott Williams \& Wilkins; 2010.

8. Schramek GGR, Stoevesandt D, Reising A, Kielstein JT, Hiss M, Kielstein H. Imaging in anatomy: a comparison of imaging techniques in embalmed human cadavers. BMC Medical Education. 2013; 13:143.

9. Demiryùrek D, Aydingöz Ü, Aksit MD, Yener N, Geyik ÖP. MR Imaging determination of the normal level of conus medularis. Clin Imaging. 2002; 26(6):375-7.
10. Jin-Tae K, Jae-Hyon B, Joohon S. Influence of age and sex on the position of the conus medularis and tuffier's line in adults. Anesthesiology. 2003;99:1359-63.

11. Rahmani M, Shabani MA, Bozorg SMV. Magnetic resonance imaging based determination of conus medullaris position in adults. Research J Biological Sci. 2009;4(2):157-9.

12. Rahmani M, Bozorg SMV, Esfe ARG, Morteza A, Khalilzadeh O, Pedarzadeh E, dkk. Evaluating the reliability of anatomic landmarks in safe lumbar puncture using magnetic resonance imaging: does sex matter?. Intern J Biomedical Imaging. 2011;10:1-5.

13. Gray H. Anatomy of the human body. [diunduh 23 April 2014]. Tersedia dari: http://www.bartleby.com/107/25.html.

14. Özer BK. Secular trend in body height and weight of Turkish adults. Anthropological Sci. 2008;116(3):191-9.

15. Frankenberg E, Jones NR. Self-rated health and mortality: does the relationship extend to a low income setting?. J Health Social Behaviour. 2004;45(4):441-52. 